could not decide satisfactorily. There was but little vesicular respiration audible in either lung; the left lung was nearly immovable; the right bronchial tubes were in a state of inflammamation. Did the ginger plug up the left bronchi? This was the case, or the left lung was in a state of chronic disease. There was less fremitus on the left side, yet bronchial sounds were abnormally audible in some places, as though there was consolidation or engorgement of the left lung; yet the fremitus was less on the left than on the right. The fremitus being less, and the left side moving so little in respiration, indicated that the ginger was in the left bronchus. What, then, was the cause of the inflammation in the right? I thought it probable, if the ginger was in the left bronchus, that (as it was described as a piece as large as the distal phalanx of the little finger) it might project into the cavity of the trachea, and propagate its irritation by continuity of structure; or that mucus impregnated with ginger might have passed into the right side, and so have caused inflammation.

February 19th, half past nine A.M.-Countenance much altered, betokening great depression; his pulse had given way and had become weak and thready; his tongue was dry and brown, his skin cool, his breathing anxious, and he complained of a good deal of pain in his chest, especially at the posterior part, between the shoulders; he was perfectly sensible, but a little inclined to coma. I feared that sinking was at hand. I ordered a blister to his chest, and commenced stimulants. At three P.M. I again saw him; he was much lower; decided collapse had appeared. At four P.M., at the request of the family, I met my friend Dr. Tyndal in consultation; he was still sinking and at five P.M. he died.

I was ordered to make a post-mortem examination of the body by the coroner, which I did at three o'clock in the afternoon of February 21st, and I regret exceedingly, that from certain very unpleasant circum stances, resulting chiefly from the disinclination of the relatives to permit the body to be examined, I was prevented from making as perfect and as minute an examination as I otherwise might have done. The jury were also waiting in the room below for my evidence. My friend Mr. Carter was present, and assisted me in the examination of the body. The lungs were so completely tied down to the parietes of the chest that it was impossible to break down the adhesions without also tearing the structure of the lungs. On laying open the laryux and trachea, nothing particular presented itself; the mucous membrane bore occasional marks of congestion, but inflammation was absent. When we arrived at the bifurcation of the trachea, at the very upper part of the right bronchus, was the fatal ginger, nearly, if not quite on a level with the point of bifurcation. The ginger was swollen and soft, and on squeezing it, a bloody mucus escaped. In this condition it measured an inch and a quarter in length, half an inch across at its widest part, and about three-eighths at its narrowest, which was also its middle. Both lungs were loaded with dark blood; partly, I apprehend, from impeded circulation, partly from gravitation \&c. after death, and partly from congestion during the last hours of life, during the stage of collapse. The cellular structure of the lungs was much altered from its natural appearance, the left lung especially. On cutting into it, a quantity of semi-purulent mucus oozed out in large quantities from every cell, and there were marks of bronchitis on the right side.

In this case, I am convinced, that if the patient's lungs had been healthy I should have pronounced on the exact seat of the ginger, for the greater part of, if not all, the disease would have been confined to the right side, and there would have been no deficiency of cellular respiration on the left side, which so complicated the case in the present instance. I remarked, that during life the right side moved more than the left in respiration. This, I apprehend, was nature's endeavour to get oxygen; for the left being diseased, and acting but little, as is evidenced by the comparative immobility of the left side, the right side expanded to get as much oxygen as possible, and the more so as the ginger offered such an impediment to the free passage of air. I would make one other remark. In this case $I$ had not the advantage of comparison, both sides being nearly equally diseased-both offering pretty nearly the same sounds on percussion; the one state being induced by chronic causes, and the other, partly by the ginger and partly by acute disease.

If my patient had been young and healthy, I do entertain a hope that his life might have been spared, for the vital powers would have been better able to endure the shock, and to sustain disease longer; added to this, the diagnosis would have been clearer. The question also presses urgently whether, if younger, and with healthy lungs, some means might not have been adopted, some expedient resorted to, for his relief; for if there be a case demanding the exercise of all the ability and all the energy of the profession, it is surely such an one as this, in which, by such a simple mechanical (?) cause, the life of a valued fellowcreature was sacrificed, and prematurely lost. The light specific gravity of the ginger was against the idea of its being moved by gravity above, especially in its swollen state; but if the ginger be permitted to remain, it must cause death; would it not be advisable, if such a substance as ginger is clearly demonstrated to be in the chest, to open the trachea as low down as possible, and to introduce an instrument to excite the irritation of coughing, in hopes of dislodging the substance, in order that it may be seized, if possible? but if this fails, I would recommend, bearing in mind that the alternative is certain death, that a long and very fine canula, enclosing a sharp stilette, with a barbed point, should be introduced through the opening, which might be passed without touching the sides of the bronchial tubes; if resistance be experienced, the stilette might be carefully protruded continually, withdrawing a little to try if the prize was caught; a stilette without a harb might be first tried.

In the case I have described, I regret only one circumstance, and that is, that I was not applied to in the morning, when the ginger was sticking in his throat, for then, if the ginger had not entered the larynx, it might have been extracted. Not long since, I was called to a boy, in imminent danger; he had a "whistle" in his throat; I could feel it with my finger, hut could not, of course, grasp it. I tickled his fauces with my finger, and the whistle was ejected with force.

I feel, Sir, that I have too much intruded, but I hope you will find the case interesting; to me it is replete with interest and information; and if its publication produces no other beneficial result, I hope it will be the means of inducing greater caution in those persons who so often go to sleep with rhubarb, tobacco, \&c. in their mouths; to such it is, indeed, a warning. My poor patient had indulged it for, I believe, twenty years, and at last it proved his death.

February 23rd, 1845 .

MODIFIED VARIOLA.

By E. ShArkey, Esq., M.D., Jersey.

The following case seems to me a fit one to be placed in juxtaposition with that detailed by Dr. Barnes in THE LANCET for the 7 th of June:-

March 1st, 1845. - A child, aged four years, never vaccinated, living in an apartment with a case of confluent small-pox, being the sixth which has occurred within a month in the family, comprising father, mother, and seven children, has complained for two or three days. On visiting her yesterday, I found her face and arms covered with a thick red rash, with spots of purpura interspersed; her gums were bleeding profusely. To-day her face ry anasarcous; lips much swollen, and covered with a highly foetid bloody incrustation, the odour precisely that which occurs in cancrum oris; the arms present a few vesicles, and about the mouth there are one or two large pustules, (if they could be properly so called, being filled with blood instead of pus ;) she is picking the bedclothes, and deglutition is nearly impossible. She died in a few hours after last report.

This case I consider interesting, as exhibiting the variety of phases which a disease may exhibit when modified by circumstances. If the case had not occurred during a severe epidemic of small-pox, and in the honse with so many who were convalescent from that disease, I should have set it down as a combination of scarlatina maligna and the "scarlatina varioloides" of Sanvages, with purpura hæmorrhagica. Occurring, however, under such circumstances, I am more disposed to consider it an irregular form of variola, modified in a strange manner by a bad constitution and impure atmosphere, and as affording another instance of the impossibility of defining nature within the strait boundaries which a desire of accurate diagnosis would sometimes induce us to establish. I may add, that there were not, to my knowledge, at the time, any cases of scarlatina in the neighbourhood, though it is true $I$ had heard of some in other parts of the town.

Winchester-place, St. Hilier's, Jersey, July, 1845.

\section{BRITISH MEDICAL JOURNALS.}

Dr. ConMack's London and Edinburgh Journal for July, contains some interesting surgical cases, with observations, by Professor Symes, illustrating the pathology of uterine and rectal polypus. The Edinburgh surgeon recommends excision to be resorted to for the removal of growths proceeding from the neck of the uterus, not possessing a malignant disposition, and excision accompanied by ligature in polypus of the uterus. We extract the following remarks:-

"In performing the operation, it is always desirable, and in 